\title{
AUDIOBOOK SEBAGAI ALAT BANTU MEMPERLANCAR KOMUNIKASI DALAM PENYEBARAN DAKWAH ISLAM PENYANDANG TUNANETRA
}

\author{
Maya Rini Handayani \\ Fakultas Dakwah dan Komunikasi - UIN Walisongo Semarang \\ Email:m4y4_h4nd4@yahoo.com
}

\begin{abstract}
$D$ isabilities people, especially muslim who are blind have the same desire with other Muslims. The similarity desire is become da'i or propagator of Islam despite having physical limitations. The main obstacle for them in the spread of Islam is communication. In order to establish the communication between the sender and the recipient should both have the same transmission and symbols. Transmission and the same symbol will be created if both of them have the same knowledge.

Unfortunately, the blind Muslims often have difficulty in gaining knowledge of Islam. This is because they can not read Islamic books. Therefore, in this article will discuss the audiobook, which is a voiced book that can be used blind Muslim to deepen knowledge of Islam. The benefits to be gained by the Islamic audiobook is facilitate communication between blind Muslims and not the blind one.
\end{abstract}

Keywords: audiobook, blind disability, Islamic dakwah

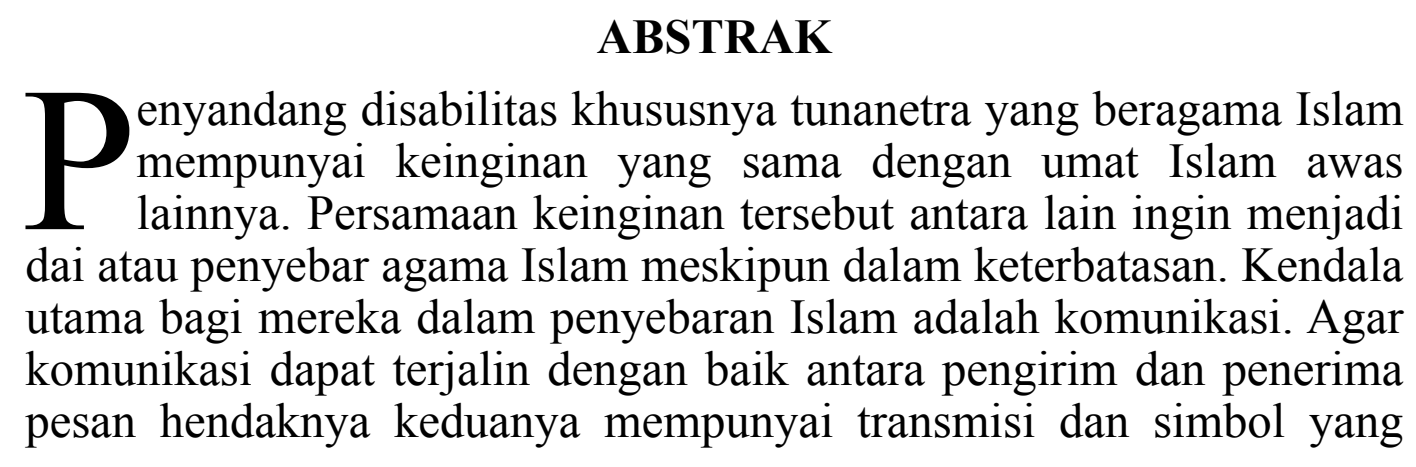


sama. Transmisi dan simbol yang sama akan tercipta jika keduanya mempunyai pengetahuan yang sama.

Sayangnya, muslim tunanetra sering mengalami kesulitan dalam memperoleh pengetahuan keislaman. Hal ini dikarenakan mereka tidak dapat membaca buku-buku Islam. Oleh sebab itu dalam artikel ini akan membahas audiobook yang merupakan sebuah buku bersuara yang dapat digunakan saudara muslim tunanetra untuk memperdalam ilmu Islam. Manfaat yang dapat diperoleh dengan adanya audiobook Islami akan memperlancar komunikasi di antara muslim tunanetra dan muslim awas.

Kata kunci : audiobook, tunanetra, dakwah Islam

\section{PENDAHULUAN}

PENGERTIAN disabilitas menurut WHO (World Health Organization) adalah istilah yang meliputi gangguan, keterbatasan aktivitas, dan pembatasan partisipasi. Kata "gangguan" pada definisi tersebut adalah sebuah masalah yang menyerang fungsi tubuh atau strukturnya. Kata suatu "pembatasan kegiatan" adalah semua kesulitan yang dialami oleh individu dalam melaksanakan tugas atau tindakan, sedangkan "pembatasan partisipasi" merupakan masalah yang dialami oleh individu dalam keterlibatan setiap situasi kehidupan. Jadi disabilitas adalah sebuah fenomena kompleks, yang mencerminkan interaksi antara ciri dari tubuh seseorang dan ciri dari masyarakat tempat dia tinggal (Disabilitas, 2015). Disabilitas atau cacat (disability) dapat bersifat fisik, kognitif, mental, sensorik, emosional, perkembangan atau beberapa kombinasi dari ini.

Sedangkan menurut UndangUndang Republik Indonesia Nomor 4 Tahun 1997 tentang Penyandang Cacat (BPKP, 2015), penyandang cacat adalah setiap orang yang mempunyai kelainan fisik dan/atau mental, yang dapat mengganggu atau merupakan rintangan dan hambatan bagi dirinya untuk melakukan aktifitas secara selayaknya, yang terdiri dari :

a. Penyandang cacat fisik;

b. Penyandang cacat mental;

c. Penyandang cacat fisik dan mental;

Menurut Reza Renaldi dalam blognya, penyandang cacat fisik dapat diartikan seseorang yang mempunyai kelainan tubuh pada alat gerak yang meliputi tulang, otot dan persendian baik dalam struktur atau fungsinya yang dapat mengganggu atau merupakan rintangan dan hambatan baginya untuk melakukan kegiatan secara selayaknya. Cacat tubuh juga disebut cacat orthopedic dan cacat muskuloskeletal yang berarti cacat yang ada hubungannya dengan tulang, sendi dan otot. Cacat ortopedi adalah salah satu jenis cacat, dimana salah satu atau lebih anggota tubuh terutama bagian tulang dan persendian mengalami kelainan (abnormal) sehingga timbul rintangan dalam melakukan fungsi gerak atau motorik (Renaldi, 2013). 
Sedangkan penyandang cacat fisik dan mental adalah seseorang (laki-laki/ perempuan) yang berusia lebih dari 18 tahun yang menderita kelainan fisik dan mental sekaligus atau cacat ganda seperti gangguan pada fungsi tubuh, penglihatan, pendengaran dan kemampuan berbicara serta mempunyai kelainan mental atau tingkah laku, sehingga yang bersangkutan tidak mampu melakukan kegiatan sehari-hari secara layak/wajar (Rustanto, 2013).

Klasifikasi atau penggolongan disabilitas, seperti yang tertuang di laman wikipedia terlihat pada tabel di bawah ini :

Tabel 1. Klasifikasi Disabilitas

\begin{tabular}{|c|c|c|c|}
\hline Tipe & Nama & $\begin{array}{c}\text { Jenis } \\
\text { disabilitas }\end{array}$ & Pengertian \\
\hline $\mathrm{A}$ & tunanetra & disabilitas fisik & tidak dapat melihat; buta \\
\hline B & tunarungu & disabilitas fisik & $\begin{array}{l}\text { tidak dapat mendengar dan/ kurang } \\
\text { dalam mendenar; tuli }\end{array}$ \\
\hline $\mathrm{C}$ & tunawicara & disabilitas fisik & tidak dapat berbicara; bisu \\
\hline $\mathrm{D}$ & tunadaksa & disabilitas fisik & cacat tubuh \\
\hline E1 & tunalaras & disabilitas fisik & cacat suara dan nada \\
\hline $\mathrm{E} 2$ & tunalaras & $\begin{array}{l}\text { disabilitas } \\
\text { mental }\end{array}$ & sukar mengendalikan emosi dan sosial. \\
\hline $\mathrm{F}$ & tunagrahita & $\begin{array}{l}\text { disabilitas } \\
\text { mental }\end{array}$ & cacat pikiran; lemah daya tangkap; \\
\hline $\mathrm{G}$ & tunaganda & $\begin{array}{l}\text { disabilitas } \\
\text { ganda }\end{array}$ & $\begin{array}{l}\text { penderita cacat lebih dari satu } \\
\text { kecacatan }\end{array}$ \\
\hline
\end{tabular}

Keterangan :

Pada kolom "Tipe" pada tabel 1 menunjukkan jenis pengelompokkan disabilitas di sebuah jenjang sekolah. Tipe A berarti untuk semua penyandang dengan disabilitas fisik tunanetra yang harus bersekolah di SLB (sekolah luar biasa). SLB A adalah sekolah yang diperuntukkan bagi orang yang tidak dapat melihat atau buta.

Di hadapan Allah, manusia mempunyai kesamaan derajat dan hak baik untuk penyandang disabilitas maupun bukan. Islam sendiri sebagai agama yang diturunkan Allah kepada Nabi Muhammad SAW adalah agama yang tidak membedakan semua umatnya, semua manusia adalah sama. yang membedakan antara manusia satu dengan yang lain adalah ketakwaannya. Seperti tersebut dalam QS. Al Hujurat ayat 13 (Surah 49 Al-Hujurat Ayah 13, 2016) sebagai berikut: 


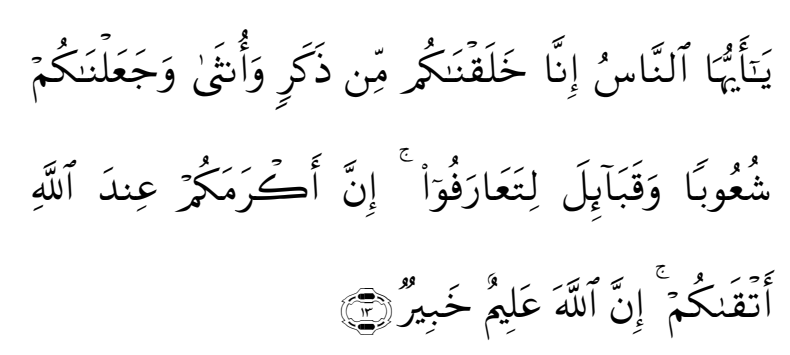

Artinya:

"Hai manusia, sesungguhnya Kami menciptakan kamu dari seorang laki-laki dan seorang perempuan dan menjadikan kamu berbangsa-bangsa dan bersukusuku supaya kamu saling kenalmengenal. Sesungguhnya orang yang paling mulia di antara kamu di sisi Allah ialah orang yang paling taqwa di antara kamu. Sesungguhnya Allah Maha Mengetahui lagi Maha Mengenal." (QS. Al Hujurat: 13)

\section{Q.S Al Hujurat ayat 13} menerangkan bahwa adanya kesamaan manusia tanpa melihat adanya jenjang sosial yang membedakan manusia di hadapan Allah SWT. Tidak memandang laki-laki atau perempuan, kaya atau miskin, cantik/ gagah atau tidak, cacat atau normal dan sebagainya. Namun jika ingin menjadi manusia mulia adalah dengan meningkatkan ketaqwaan sehingga derajatnya akan mulia di hadapan Allah SWT. Dalam Islam seorang penyandang cacatpun mempunyai hak dan kewajiban yang sama dengan manusia lainnya, begitu pula dalam kegiatan berdakwah.

Dakwah mempunyai arti panggilan, seruan atau ajakan, ini jika ditinjau dari segi bahasa dakwah.
Bentuk perkataan tersebut dalam bahasa Arab adalah mashdar, sedang bentuk kata kerja atau fi'ilnya adalah $d a$ 'a yad'u yang berarti memanggil, menyeru atau mengajak (Saleh, 1993). Dalam mensosialisasikan kegiatan dakwah tersebut dapat dilakukan dengan cara melalui lisan (dakwah bi al-lisan), tulisan (wa bi al-qalam) dan perbuatan nyata (wa bi al-hal). (Munir, 2006).

Dari penjelasan di atas tentang dakwah, tidak ada sebuah katapun yang mensyaratkan dakwah hanya dilakukan oleh orang yang normal ataupun sehat fisiknya. Seorang penyandang cacatpun tetap dapat melakukan kegiatan dakwahnya walaupun dengan menggunakan metode yang berbeda. Seorang tunanetra, disebabkan mereka tidak bisa melihat maka mereka dapat melakukan kegiatan berdakwah dengan menggunakan lisan (dakwah bi al-lisan). Penyandang cacat tunanetra tersebut menyadari bahwa belajar merupakan kewajiban bagi setiap muslim. Seperti yang tercantum dalam Q.S Al Alaq ayat $1-5$ di bawah ini :

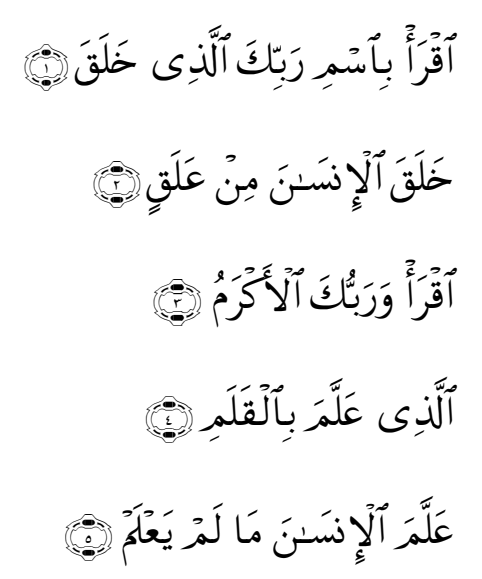

\section{Artinya :}

1. Bacalah dengan (menyebut) nama Tuhanmu yang menciptakan, 
2. Dia telah menciptakan manusia dari segumpal darah,

3. Bacalah, dan Tuhanmu lah yang paling pemurah,

4. Yang mengajar (manusia) dengan perantaran kalam

5. Dia mengajar kepada manusia apa yang tidak diketahui

Dari Q.S Al Alaq ayat 1-5 tersebut, pada kata "bacalah" terdapat pengulangan sebanyak $2 \mathrm{x}$ yang menunjukkan betapa pentingnya kata "bacalah". Bagaimanadengan saudarasaudara muslim yang mempunyai cacat tunanetra?. Bagaimana cara mereka berdakwah jika membaca saja mereka tidak mampu?. Bagaimana cara menyampaikan dakwah (komunikasi) dengan muslim awas lainnya?. Beberapa pertanyaan ini akan mudah dijawab jika muslim tersebut awas atau sehat mata, namun berbeda kondisi dengan muslim tunanetra. Muslim tunanetra harus mempunyai metode dan alat bantu yang khusus bagi mereka.

Contoh metode dan alat bantu bagi muslim tunanetra adalah menggunakan huruf braille. Untuk "membaca" Al Quran, muslim tunanetra sudah menggunakan Al Qur'an Braille untuk "membacanya". Huruf braille adalah sejenis sistem tulisan sentuh yang digunakan oleh orang buta. Sistem ini diciptakan oleh seorang Perancis yang bernama Louis Braille yang buta disebabkan kebutaan waktu kecil. Ketika berusia 15 tahun, Braille membuat suatu tulisan yang diperuntukkan bagi tentara agar dapat membaca tulisan di tempat gelap. Tulisan inilah yang dinamakan sebagai huruf Braille. (Wikipedia, 2016).
Meskipun sudah ada Al Qur'an dan buku-buku braille, namun belum mencukupi kebutuhan akan ilmu pengetahuan lainnya terutama bukubuku untuk berdakwah yang belum behuruf braille. Kendala kekurangan bahkan ketidakadaan buku dakwah braille berimbas pada ketidaklancaran komunikasi antara muslim tunanetra dengan muslim awas.

Mengapa hal tersebut dapat terjadi? Buku adalah gerbang dunia dan aktifitas yang berhubungan dengan buku adalah membaca. Sedangkan membaca adalah kegiatan yang tidak mungkin dilakukan oleh muslim tunanetra. Terdapat solusi lain bagi tunanetra yang ingin membaca buku selain menggunakan buku braille yaitu menggunakan audiobook atau "buku berbicara". Buku berbicara adalah sebuah rekaman digital dari buku-buku yang sudah direkam terlebih dahulu untuk memudahkan penyandang tunanetra "membaca" sebuah buku dengan cara mendengarkan file audio tersebut.

\section{PEMBAHASAN}

\section{Pengertian Audiobook}

Audiobook adalah A book that has been read and recorded on cassette tape, $C D$ or digital format (Wikipedia, 2016), yang terjemahannya adalah sebuah buku yang sudah dibaca dan direkam ke dalam pita kaset, $\mathrm{CD}$ atau format digital. Audiobook adalah istilah yang digunakan untuk menggambarkan buku yang dibacakan. Jadi dengan menggunakan audiobook orang dapat "membaca" buku dengan cara cukup mendengarkan file audiobooknya saja. 
Ide audiobook sebenarnya sudah dirintis sejak tahun 1931. Sejarah audiobook bermula pada tahun 1931 atau tepatnya pada Kongres Amerika program buku yang dapat berbicara atau talking book program telah ditetapkan sebagai upaya membantu tuna netra yang tidak dapat membaca buku cetak. Bukubicara dikembangkan pertama kali oleh Yayasan Orang Buta Amerika pada tahun 1932 dan diterbitkan secara massal pada tahun 1933, hingga akhirnya tahun 1996 didirikanlah Audie Award oleh Audio Publisher Association untuk audiobook yang berprestasi. Audie Award ini merupakan penghargaan yang setara dengan Piala Oscar. Para nominasi Audie Award biasanya akan diumumkan pada bulan Januari setiap tahunnya. Adapun para pemenang Audie Award baru diumumkan pada acara gala pesta di musim semi yang bertepatan dengan Book Expo America. (Wikipedia, 2016).

Kelebihan audiobook untuk penyandang tunanetra yang tersimpan dalam pita kaset, $C D$ ataupun format file adalah mereka hanya perlu mendengarkan kata demi kata tanpa perlu membaca text secara langsung. Apabila dalam proses mendengarkan ternyata ada yang perlu diulang, maka pendengar hanya perlu menekan tombol rewind atau previous untuk mendengarkan kembali. Audiobook di teknologi modern sekarang ini sudah dilengkapi dengan penggunaan efek suara dan musik, sehingga menambah seru dan keasyikan tersendiri bagi penyandang tunanetra. Suasana cerita akan lebih terlihat nyata sehingga mereka pun akan dapat menceritakan kembali cerita tersebut seperti manusia normal melihat melalui video atau film.

Bahkan narator atau pembaca naskah audiobook sekarang ini sudah membekali diri mereka dengan teknik penghayatan dan intonasi. Pembacaan untuk text yang ditulis di naskah (teori) dan text yang berisi percakapan, akan terdengar berbeda. Hal tersebut dikarenakan narator memberikan intonasi (penekanan) suara yang berbeda sehingga memudahkan bagi pendengarnya.

\section{Audiobook untuk Berkomunikasi}

Komunikasi itu sendiri mempunyai pengertian yang berbedabeda. Menurut Jane Pauley dalam buku karangan Liliweri (2011, hal 7), komunikasi mempunyai 3 komponen yaitu informasi, transmisi dan simbol yang sama. Apabila salah satu komponen tidak ada maka itu bukanlah arti dari komunikasi. Komunikasi diartikan sebagai transmisi informasi dan transmisi pengertian dengan menggunakan simbol-simbol yang sama antara pemberi dan penerima informasi. Dalam berkomunikasi, informasi yang disampaikan juga haruslah mengandung data yang valid, akurat dan dapat dipercaya. Untuk memenuhi ke 3 unsur data tersebut (valid, akurat dan dapat dipercaya) seseorang haruslah banyak membaca baik buku, koran, makalah, laporan dan sebagainya.

Bagi orang awas, membaca bukanlah masalah besar namun tidak bagi penyandang tunanetra. Mereka "membaca" melalui telinga sehingga semua informasi yang mereka terima sebagian berasal dari telinga. Jikapun "membaca", penyandang tunanetra 
biasanya membaca menggunakan huruf braille. Adapun kelemahan buku braille adalah :

1. Mahal harganya karena kertas yang digunakan bukan kertas biasa namun kertas karton dengan ketebalan tertentu

2. Terlalu tebal sebab ketebalan kertas yang berlipat dari kertas biasa

3. Terlalu berat untuk di bawabawa sebab ketebalan dan ukuran kertas yang besar dan lebar

4. Masih sedikitnya buku biasa yang dirubah menjadi buku braille

Komunikasi antara penyandang disabilitas dan orang awas dapat terjalin dengan baik jika si pengirim dan penerima pesan menggunakan ke 3 komponen komunikasi dengan benar. Akan terjadi misscommunication (salah persepsi dalam komunikasi) jika salah satu dari ketiga komponen tersebut tidak sesuai antara pengirim dan penerima pesan. Oleh sebab itu penyandang tunanetra membutuhkan bekal ilmu dari buku-buku berbicara agar komunikasi (pembicaraan) tersebut tersampaikan dengan baik.

Terdapat beberapa aturan atau etika berkomunikasi antara si pembawa pesan (orang awas) dengan si penerima pesan (penderita tunanetra), antara lain (Suri, 2014):

1. Perkenalkan diri (sebutkan nama) si pembawa pesan jika ingin berbicara dengan si penerima pesan yang tunanetra. Hal ini disebabkan mereka tidak paham dengan si pembawa pesan hanya berdasarkan suara (kecuali jika sudah berteman akrab dengan si penerima pesan)

2. Hendaknya si pembawa pesan berbicara secara alami dan jelas tidak perlu menggunakan nada tinggi dan suara yang keras, sebab si penerima pesan meskipun tunanetra namun bukan tunarungu (kecuali jika si penerima pesan mengalami cacat fisik ganda maka cara berkomunikasi bisa berbeda)

3. Sangat penting jika berbicara dengan tunanetra menggunakan gestur (gerakan tubuh) dan intonasi dalam berkomunikasi, sebab hal ini akan sangat membantu terutama bagi penderita tunanetra sejak bayi. (Handayani, 2015, p154)

4. Tidak perlu menghindari katakata yang berhubungan dengan mata seperti "lihat", "menonton", "memandang".

5. Jika si pembawa pesan hendak menyampaikan pesannya pada si penerima yang tunanetra hendaknya sebut nama si penerima pesan (terutama jika berada dalam kondisi berkelompok) atau tepuk pundak si penerima pesan pada saat akan memulai pembicaraan.

6. Antara pembawa dan penerima pesan hendaknya berbicara secara langsung tanpa menggunakan/ melalui orang ketiga.

7. Jika berkomunikasi dalam diskusi kelompok, perkenalkanlah pula orang lain yang hadir agar penerima pesan tunanetra dapat berkomunikasi dengan yang lain 
8. Jika komunikasi dalam diskusi sudah selesai maka tariklah kesimpulan untuk membantu si penerima pesan menangkap inti dari komunikasi

9. Mempergunakan bahasa akurat dan spesifik. Contohnya ketika memberikan arah, akan lebih baik jika berkata "pintu di sebelah kiri Anda", bukan "pintu ada di sana". Berkomunikasi dengan tunanetra hendaknya menggunakan penjelasan yang lebih detil sebab tunanetra "melihat" menggunakan perabaan pada sebuah benda. (Handayani, 2015, p61)

10. Usahakan si pembawa pesan jika berbicara hanya satu orang jika lebih dari satu orang maka berkomunikasi secara bergantian agar tidak membingungkan si penerima pesan

11. Bertanyalah selalu apakah informasi yang diutarakan si pembawa pesan dapat di terima dengan baik oleh si penerima pesan, jangan tinggalkan mereka dalam keadaan kebingunan

Jenis Audiobook yang berkembang dewasa ini ada 2 macam, yaitu unabridged audiobook dan abridged audiobook. Unabridged audiobook adalah audiobook dengan pembacaan kata per kata yang bersumber dari sebuah buku cetak. Adapun abridged audiobook adalah kata-kata yang tidak sesuai dengan buku cetaknya, tetapi tidak mengurangi makna kalimat. Biasanya pembuat audiobook memilih abridged audiobook untuk penghematan biaya.

Sebenarnya audiobook bukanlah sebuah produk baru, hanya istilah dari audiobook itu sendiri yang baru akhirakhir ini terdengar. Dahulu ketika televisi belum sebanyak sekarang jumlahnya, radio menjadi alternatif masyarakat umum. Sandiwara radio menjadi puncak kejayaan program siaran hampir di setiap radio. Ketika masih anak-anak dulu, orang tua kita juga sering membeli kaset dari Sanggar Cerita yang berisi tentang sandiwara dongeng rakyat Indonesia asli ataupun cerita fiksi lainnya. Sebenarnya sandiwara radio dan rekaman dari Sanggar Cerita adalah contoh audiobook.

Di negara Thailand bahkan sudah ada aplikasi untuk smartphone yang di beri nama Read for The Blind. Aplikasi tersebut wujud kepedulian kerajaan Thailand bagi rakyatnya yang tunanetra. Aplikasi tersebut didanai kerajaan Thailand dengan tujuan agar warganya dapat mengunduh aplikasi tersebut gratis sehingga setiap warga negara dapat membuat audiobook dengan mudah dan murah. (Handayani, 2014, p79).

Aplikasi tersebut memberi dampak meningkatnya secara signifikan jumlah audiobook di Thailand sehingga perbedaan pengetahuan antara tunanetra dan orang awas menjadi sempit. Berkebalikan dengan Indonesia, pemerintah Indonesiamasih belum maksimal dalam mendukung terciptanya audiobook bagi tunanetra sehingga kesenjangan pengetahuan semakin lebar yang berdampak pada kesenjangan komunikasi.

Sebagai umat muslim yang mempunyai fisik sehat, sebaiknya kita membantu penyandang tunanetra muslim dengan memperbanyak 
audiobook berdasarkan buku-buku Islam. Terdapat beberapa cara yang dapat dilakukan untuk memperbanyak audiobook Islam :

1. Merekam suara kita sendiri yang membaca buku-buku Islam kemudian menyerahkan rekaman tersebut ke griya/ yayasan tunanetra (walaupun belum melalui proses edit)

2. Menjadi sukarelawan narator untuk perekaman audiobook untuk griya/yayasan tunanetra

3. Merekam sendiri audiobook yang berasal dari sebuah film, contohnya adalah film Ayat-ayat Cinta. Dari film Ayat-ayat Cinta tersebut kita ambil suaranya saja, sedangkan untuk adeganadegan yang tidak bisa dilihat oleh tunanetra diganti dengan suara, seperti misalnya adegan membuka pintu. Untuk adegan membuka pintu maka, pembuatan audiobook harus lebih detil ada suara pintu terbuka (untuk memberikan daya imajinasi) dan suara narator mengatakan pintu terbuka.

\section{PENUTUP}

Audiobook yang kita buat ataupun orang lain buat, tentunya akan membawa manfaat yang luar biasa bagi pengguna (tunanetra). Manfaat tersebut akan semakin berdaya jika audiobook yang dibuat adalah audiobook yang berisi materi dakwah. Dengan audiobook, penyandang tunanetra cukup mendengarkan audiobook untuk menambah ilmu pengetahuan tanpa harus membaca secara langsung.
Efek dari banyaknya audiobook dakwah dapat membantu saudara tunanetra muslim untuk lancar berkomunikasi dengan saudara muslim awas. Hal tersebut disebabkan banyaknya tunanetra muslim yang diminta menjadi dai/penceramah di lingkungan tempat mereka tinggal. Banyaknya ilmu yang diserap membuat tunanetra muslim menjadi semakin percaya diri berkomunikasi dan berhadapan dengan muslim awas sebab komunikasi yang terjalin menjadi jelas penerimaan antara pengirim dan penerima pesan.

Sebenarnya banyak situs-situs penyedia audiobook yang bersifat free atau gratis. Contoh situs-situs tersebut adalah www.librophile.com, www. bookbox.com, www.ejunto.org dan http://www.freeaudiobooks.co.uk/.

Situs www.librophile.com berisi koleksi fiksi dan dongeng anak berbahasa Inggris, seperti Twenty Thousand Leagues Under the Sea karya Jules Verne, Art of War karya Sun Tzu, Anne of The Island karya Lucy Maud Montgomery, Alexander the Great karya Jacob Abbot dan sebagainya. Ada satu audiobook dari situs tersebut yang berhubungan dengan ibadah yaitu Pilgrim's Progress karya John Bunyan namun audiobook tersebut menjelaskan tentang perjalanan seorang kristen untuk menemukan surganya. Untuk www.bookbox.com berisi dongeng dan belajar untuk anak-anak dengan pilihan berbagai bahasa seperti Arabic, Asante Twi, Assamesse, Bengali, English,Indonesian, Mandarin, Turkey hingga Urdu. Contoh audiobook di situs bookbox.com adalah Turtle's Flute, The Little Pianist, Santa's 
Christmast, The Greatest Treasure, The Four Friends dan masih banyak lainnya, namun terlihat tidak ada yang membahas tentang dongeng atau cerita Islam bahkan dongeng yang ada adalah tentang cerita kristen yaitu santa natal.

Situs berikutnya adalah www. ejunto.org tentang biografi, sejarah dan cerita dari orang-orang hebat di dunia yang berbahasa Inggris. Pada situs tersebut berisi audiobook tentang American History yaitu The Autobiography of Benjamin Franklin, George Washington: Biography, John Adam Biography hingga tentang filosofi seperti The Apology, The Social Contract hingga Civil of Disobedience. Dari judul audiobook tersebut terlihat tidak ada yang membahas tentang Islam atau sejarah Islam atau bahkan tokoh Islam sama sekali. Sedangkan situs http:// www.freeaudiobooks.co.uk/ berisi audiobook mulai dari seni, bisnis, biografi, anak-anak, pendidikan, bahasa, olah raga hingga perjalanan. Situs ini selain menyediakan audiobook gratis dengan jalan diunduh (meskipun versi trial) juga digunakan untuk menjual audiobook. Sayangnya audiobook di situs ini tidak ada satupun audiobook yang berhubungan tentang Islam. Kondisi inilah yang tentunya merupakan kewajiban muslim awas untuk membantu tunanetra muslim dalam memperoleh ilmu agama.

\section{DAFTAR PUSTAKA}

Al Qur'an Online. 2016. "Surah 49 Al-Hujurat Ayah 13", dalam http://alim.org/library/quran/ayah/ compare/49/13/, diakses 15 Mei 2016

BPKP. 2016. "BPKP - Unduhan UU RI No.4 Tahun 1997" dalam www. bpkp.go.id/uu/filedownload/2/46/442. bpkp, diunduh 14 Mei 2016

Handayani, Maya Rini. (2014). Audiobook untuk Penyandang Disabilitas SLB - A Dria Adi Semarang. Laporan PKM (Pengabdian Kepada Masyarakat) Distis 2014. p79

Handayani, Maya Rini. (2015). Audiobook Islami sebagai Media Pembelajaran calon Dai Tunanetra Komunitas Sahabat Mata Semarang. Laporan PKM (Pengabdian Kepada Masyarakat) Distis 2015. p154

Idwin, "Aplikasi untuk Mendengarkan Audiobook" dalam http://idwinphone.com/audibleaplikasi-untuk-mendengarkanaudiobook, diakses 26 Juni 2016

Liliweri, Alo Drs. (2011). Dasardasar Komunikasi Antarbudaya. Cetakan V. Yogyakarta :Pustaka Pelajar. p7

Mitranetra, "Daisy Indonesia" dalam http://www.mitranetra.or.id/ daisy/index.asp?gm $=1 \& 1 \mathrm{~m}=12$, diakses 25 Juni 2016

Munir, M dan Ilaihi, Wahyu (2006). Manajemen Dakwah. Cetakan ke 1. Jakarta : Prenada Media. p1

Renaldi, Reza. 2013. "Penyandang Cacat Tubuh dan Permasalahannya" dalam http:// rezarenaldi09.blogspot.com/2013/03/ penyandang-cacat-tubuh-'dan.html, sumber asli : Direktorat Jenderal Pelayanan dan Rehabilitasi Sosial. 2008. "Panduan Khusus Pelaksanaan Bimbingan Sosial Penyandang 
Cacat Tubuh dalam Panti". Jakarta: Departemen Sosial RI, diakses $16 \mathrm{Mei}$ 2016

Rosgani. 2009. "Audiobook, Buku dengan Format Suara", dalam http://www.feedberry. com/2009/10/18/audiobook-bukudengan-format-suara/, diakses 25 Juni 2016

Rustanto, Bambang. 2013. "Konsep Disabilitas", dalam http://bambang-rustanto.blogspot. com/2013/08/konsep-disabilitas.html, diakses 17 Mei 2016

Saleh, Abd Rosyad (1993). Manajemen Dakwah Islam. Cetakan ke 3. Jakarta : PT Bulan Bintang. p7

Suri. 2014. "Komunikasi yang Efektif dengan Tuna Netra dan Orang dengan Penglihatan Lemah" dalam http://www.dnetwork.net/blog/
Komunikasi-yang-efektif-denganTuna-Netra-dan-Orang-denganPenglihatan-Lemah, di akses 8 Juli 2016

Wikipedia. 2016. "Braille" dalam http://id.wikipedia.org/wiki/Braille, diakses 18 Mei 2016

Wikipedia. 2016. "Disabilitas" dalam http://id.wikipedia.org/wiki/ Disabilitas, diakses 14 Mei 2016

Wikipedia. 2016. "Audiobook" dalam http://id.termwiki.com/ EN:audio_book, diakses 15 Juni 2016 Wikipedia. 2016. "Sejarah dan Perkembangan Audiobook' dalam http://www.audiobuku.com/sejarahdan-perkembangan-audibook, diakses 15 Juni 2016 